\title{
sciendo
}

\section{CARCASS AND MEAT QUALITY OF LAMBS FROM THIN-TAILED AND FAT-TAILED BREEDS AT FIVE DIFFERENT SLAUGHTER WEIGHTS*}

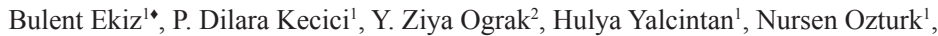 \\ Akin Yakan ${ }^{3}$, Gulcan Demirel ${ }^{4}$, Omur Kocak ${ }^{1}$, Alper Yilmaz ${ }^{1}$
}

\author{
${ }^{1}$ Department of Animal Breeding and Husbandry, Istanbul University-Cerrahpasa, Buyukcekmece, \\ Istanbul, Turkey \\ ${ }^{2}$ Department of Animal Breeding and Husbandry, Faculty of Veterinary Medicine, Sivas Cumhuriyet \\ University, Sivas, Turkey \\ ${ }^{3}$ Department of Genetics, Faculty of Veterinary Medicine, Hatay Mustafa Kemal University, Hatay, \\ Turkey \\ ${ }^{4}$ Department of Animal Nutrition and Nutritional Diseases, Istanbul University-Cerrahpasa, \\ Buyukcekmece, Istanbul, Turkey \\ •Corresponding author: bekiz@istanbul.edu.tr
}

\begin{abstract}
In lamb production, deciding the optimal slaughter weight (SW) has great importance on product quality. The aim of the study was to determine the optimum SW for lambs from a thin-tailed breed (Kivircik) and a fat-tailed breed (Kangal Akkaraman) in order to get high-quality meat and carcass. Kivircik $(n=60)$ and Kangal Akkaraman $(n=59)$ lambs were allotted to five SW groups $(20$, 28, 36, 44 and $52 \mathrm{~kg}$ ). In Kivircik lambs, backfat thickness and fatness score gradually increased in parallel with the increase in SW, while the increase in the tail fat and kidney knob and channel fat (KKCF) proportions were observed by up to $36 \mathrm{~kg}$. In Kangal Akkaraman lambs, evident increases in fatness parameters, except tail fat proportion, were observed when the $\mathrm{SW}$ increased from $44 \mathrm{~kg}$ to $52 \mathrm{~kg}$. Meat pH, Warner Bratzler shear force (WBSF) and cooking loss values were not influenced by SW in lambs of both breeds. As SW increased in Kivircik lambs, there was a significant decrease in meat lightness and an increase in yellowness. In Kangal Akkaraman breed, lambs slaughtered at $20 \mathrm{~kg}$ and $28 \mathrm{~kg}$ had higher $L^{*}$ values, and lower a* and $C^{*}$ values

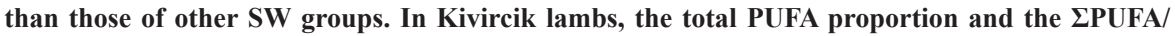
¿SFA ratio were lower in SW-44 and SW-52 groups than those of SW-20 and SW-28 groups. Decreases of these parameters were in SW-52 group in Kangal Akkaraman lambs. In meat samples of both breeds, SW-52 groups had a lower $\Sigma n-3$ proportion and a higher $\Sigma n-6 / \Sigma n-3$ ratio than other SW groups. In Kivircik lambs, the panellists evaluated the meat of SW-20 and SW-28 groups as tender compared to those in SW-44 and SW-52 groups. In Kangal Akkaraman breed, flavour intensity in the meat of SW-52 lambs was higher than those of SW-20 and SW-28 groups. Results of the study indicate that slaughtering of lambs at $20 \mathrm{~kg}$ and $28 \mathrm{~kg}$ in both breeds provided bet-
\end{abstract}

*Funding: Scientific Research Projects Coordination Unit of Istanbul University-Cerrahpasa (ONAP-39573). 
ter meat quality but caused lower carcass weight. Therefore, slaughtering Kivircik and Kangal Akkaraman lambs at $20 \mathrm{~kg}$ and $28 \mathrm{~kg}$ live weight might be recommended especially to farmers, who aim to obtain high-quality lamb meat. In this case, it should not be ignored that the amount of meat produced will be less. On the other hand, slaughtering lambs at about $44 \mathrm{~kg}$ weight could be recommended to farmers, who aimed to obtain as much quality lamb carcasses as possible without any negative influence on meat quality.

Key words: slaughter weight, tail type, meat quality, fatty acids, carcass quality

Sheep farming provides an important contribution to meat supply in the Middle East, Mediterranean and some Balkan countries, which also include Turkey. In these countries, many indigenous sheep breeds adapted to the natural nutritional resources and climatic conditions of the region they are bred. Sheep breeds reared in Middle Eastern countries can be divided into two groups as fat-tailed and thin-tailed according to their tail structures. There are major differences between these two groups in terms of localization of fat tissue on carcass. In fat-tailed breeds, as an important amount of adipose tissue is accumulated in the tail, other carcass parts are less fatty compared to thin-tailed breeds (Karabacak and Boztepe, 2007). Besides, there may be differences among sheep breeds regarding muscle collagen content and solubility. Differences in collagen characteristics and accumulation of fat tissue may cause differences in carcass and meat quality between sheep breeds (Martínez-Cerezo et al., 2005).

In the Middle Eastern countries where the Muslim population is very dense, pork consumption is very limited. Therefore, almost all of the red meat needs in these countries are met from sheep and cattle species (Ekiz et al., 2019 a). Sheep stock in Turkey was 37.3 million head in 2019 (TUIK, 2020). According to FAO statistics in 2018, Turkey ranked 8th place in the world in terms of the number of sheep (FAO, 2020). Sheep breeding is traditionally carried out by small family-type enterprises and is of great importance for the income, nutrition and culture of the rural population (Gursoy, 2006). Meat obtained from mutton or lamb and kebabs made with mutton are highly appreciated by Turkish consumers (Ekiz et al., 2009; Gursoy, 2006). Many indigenous sheep breeds, which are well suited to a variety of harsh geographic and climatic conditions, are reared in the country. While fat-tailed sheep breeds are generally reared in the inland, thin-tailed breeds are mostly reared in the coastal regions of Turkey (Anonymous, 2009). Among the sheep breeds, Akkaraman, a fat-tailed breed, is the most commonly reared breed in the country (Kayalık and Bingöl, 2015). Kangal Akkaraman is one of the varieties of Akkaraman breed and reared mostly in Sivas province where the winter months are quite harsh and cold. Kangal Akkaraman is known for its largest framed body and highest growth rate among the indigenous sheep breeds of Turkey (Anonymous, 2009; Tufan and Akmaz, 2001). On the other hand, among the thin-tailed sheep breeds, Kivircik is the most numerous breed (Kayalık and Bingöl, 2015). Kivircik is a medium sized indigenous breed of the Marmara region and it is also bred in Balkan countries such as Bulgaria and Greece (Ekiz et al., 2018). Turkish consumers evaluate the meat of the Kivircik lambs as the best quality meat among the breeds raised in Turkey and 
Kivircik meat is mostly sold at higher prices (Ekiz et al., 2018, 2020; Yalcintan et al., 2018). Kivircik lambs do not have a rapid growth rate, and average daily gain of male Kivircik lambs was reported as 168-225 g (Ekiz et al., 2012 a, 2019 a).

Lamb carcass and meat quality might significantly be influenced by SW (Cañeque et al., 2001; Santos-Silva et al., 2002; Díaz et al., 2003). Therefore, to benefit from the meat production potential of lambs, it is of great importance to determine the highest SW which will not lead to a reduction in lamb carcass and meat quality. Studies have been carried out to investigate carcass and meat quality characteristics of Kivircik lambs (Ekiz et al., 2012 a, 2019 a, b; Yalcintan et al., 2018) and Akkaraman lambs (Aksoy et al., 2018, 2019; Khadre and Karabacak, 2018) in a constant SW. However, the studies on the meat quality characteristics of Kangal Akkaraman lambs, and the carcass and meat quality characteristics at different slaughter weights for both breeds are quite limited. The aim of the current study was to determine the optimum SW to produce high-quality carcass and meat in thin-tailed Kivircik and fat-tailed Kangal Akkaraman lambs. For this purpose, carcass characteristics, instrumental and sensory meat quality characteristics of lambs slaughtered at 20, $28,36,44$ and $52 \mathrm{~kg}$ weights were investigated, comparatively. The results of the study may assist in deciding the most appropriate slaughter weight, which will not lead to a reduction in carcass and meat quality, of Kivircik and Kangal Akkaraman lambs.

\section{Material and methods}

The experimental procedures of the study were approved by the Ethic Committee of Istanbul University (Approval No: 2013/113).

\section{Animals}

A total of 119 male lamb carcasses from Kivircik $(n=60)$ and Kangal Akkaraman $(n=59)$ breeds were used in the study. Thin-tailed Kivircik lambs were purchased among the purebred herds involved in the "Breeding of Kivircik Sheep Raised in Breeder Conditions in Kirklareli Province" project carried out by the Ministry of Agriculture and Forestry. Kirklareli is the province where the purebred Kivircik sheep is the most widely bred. Fat-tailed Kangal Akkaraman lambs were purchased among the purebred herds involved in the "Breeding of Kangal Akkaraman Sheep Raised in Breeder Conditions in Sivas Province" project. To ensure that the selected animals are representative of the breeds and to avoid possible sire effects, purebred Kangal Akkaraman lambs were obtained from 4 different farms, while purebred Kivircik lambs were purchased from 9 different farms. These farms were randomly selected, where male lambs were intensively fed with ad-libitum commercial concentrate feed [mean crude protein: $17.45 \%$ (min.: 16.89\% and max.: 18.26\%); mean metabolisable energy: $10.89 \mathrm{MJ} / \mathrm{kg}$ dry matter (min.: $10.53 \mathrm{MJ} / \mathrm{kg}$ and max.: $11.23 \mathrm{MJ} / \mathrm{kg}$ )] and hay until slaughter. In these farms, lambs were started to be fed with concentrate feed and hay at the age of 1 week and were weaned when they were 3-3.5 months old. 
Five SW groups were studied in both breeds: i. $20 \mathrm{~kg}(18.0-21.9 \mathrm{~kg}$; SW-20), ii. $28 \mathrm{~kg}(26.0-29.9 \mathrm{~kg} ; \mathrm{SW}-28)$, iii. $36 \mathrm{~kg}$ (34.0-37.9 kg; SW-36), iv. 44 (42.0-45.9 kg; SW-44) and v. $52 \mathrm{~kg}(50.0-53.9 \mathrm{~kg} ; \mathrm{SW}-52)$. All lambs in the selected farms were weighed the day before the slaughter, and the lambs that could be included in the SW groups were identified. Within each breed, twelve lambs in each SW group were randomly selected to slaughter. However, one lamb in the SW44 group in the Kangal Akkaraman breed was removed from the study since it had a pre-slaughter weight below the limits for that SW group.

\section{Slaughter procedures and carcass characteristics}

Kangal Akkaraman lambs were slaughtered in a commercial slaughterhouse in Sivas, while Kivircik lambs were slaughtered at the Istanbul University Experimental Slaughterhouse. Similar slaughter procedures were carried out in both slaughterhouses. Lambs were slaughtered after 75 min lairage. Immediately prior to the bleeding, pre-slaughter weights of lambs were recorded after an overnight (about $16 \mathrm{~h}$ ) fasting. After the slaughter, non-carcass components were removed, and carcasses were chilled at $4^{\circ} \mathrm{C}$ for $24 \mathrm{~h}$. Then, cold carcass weights were recorded. Kangal Akkaraman lamb carcasses were transported to Istanbul University Experimental Slaughterhouse by a frigorific vehicle at $4^{\circ} \mathrm{C}$.

At post-mortem 96th hour, lamb carcasses were classified for fatness and conformation according to the EUROP carcass classification system (European Union, 1992; European Union, 1993). In order to analyse the fatness and conformation classification data statistically, the scores given to lamb carcasses were converted into a 1-15 scale according to the description by Johansen et al. (2006). Afterwards, kidney-knob and channel fat (KKCF) was separated from the carcass and weighed. $M$. longissimus dorsi (LD) section area was measured between last thoracic and first lumbar vertebrae by a Placom planimeter (KP90N, Koizumi, Nagoya Japan). Backfat thickness was measured from the same section by a digital calliper. Afterwards, tail-fats were removed from carcasses and weighed. Cold carcass weight was presented in two ways: i) including tail-fat weight (CCW1) and ii) without tail-fat weight (CCW2). Dressing percentage was also calculated using both intact cold carcass weight (DP1) and CCW2 (DP2).

\section{Instrumental meat quality analyses}

Carcass $\mathrm{pH}$ was measured directly on $L D$ muscle between 12 th and 13 th thoracic vertebrae at $24 \mathrm{~h}$ post slaughter $\left(\mathrm{pH}_{24}\right)$ using a digital $\mathrm{pH}$ meter (Testo 205, Testo AG, Lenzkirch, Germany). To assess instrumental meat quality, $L D$ muscles from the left side of the carcasses were removed at $96 \mathrm{~h}$ post-mortem. Drip loss was measured using the meat samples cut from 5 th thoracic vertebrae by suspending the samples for $24 \mathrm{~h}$ at $4^{\circ} \mathrm{C}$ (Honikel, 1998). Expressed juice was measured by the modified Grau and Hamm pressure method (Beriain et al., 2000 a). Cooking loss was measured from $L D$ muscle samples cut from 8-13th thoracic vertebrae. Meat samples were placed in polyethylene bags and cooked in a water bath $\left(80^{\circ} \mathrm{C}\right.$ ) for $45 \mathrm{~min}$ (Honikel, 1998). Meat samples from the cooking loss analysis were used for Warner-Bratzler shear force (WBSF) analysis. Six sub-samples $(1 \times 1 \mathrm{~cm}$ thick, $2.5-3 \mathrm{~cm}$ length $)$ were 
analysed using Instron Testing device (Model-3343, Instron Corp., Norwood, MA, USA). Colour measurement of $L D$ muscle was performed after $1 \mathrm{~h}$ blooming on cut surface of the slices. Meat L* (lightness), a* (redness), b* (yellowness), C* (Chroma) and $\mathrm{H}^{*}$ (hue angle) values were determined by Minolta chromometer (Minolta CR 400, Minolta Camera Co., Osaka, Japan).

Meat samples sliced from the $L D$ muscle at the 6th and 7th thoracic vertebrae were vacuum packaged and stored at $-18^{\circ} \mathrm{C}$ until the fatty acid composition analysis. Gas chromatography-mass spectrometry (HP Agilent 6890/5972, Santa Clara, CA, USA) was used in fatty acid analyses. Procedures specified previously by Ekiz et al. (2019 a) were applied in meat fat extraction and fatty acid analyses.

\section{Meat sensory assessment}

Procedures specified previously by Ekiz et al. (2019 a) were also used in meat sensory analyses. Briefly, $L D$ muscle between 2-4th lumbar vertebrae was used for sensory analyses. Samples were packaged under vacuum and stored at $-18^{\circ} \mathrm{C}$ until sensory assessment. One day prior to each panel evaluation, frozen samples were removed from the freezer and thawed at $4^{\circ} \mathrm{C}$ for $24 \mathrm{~h}$. The samples were cooked in a $180^{\circ} \mathrm{C}$ oven until the internal temperature reached $80^{\circ} \mathrm{C}$. Each cooked sample was cut into 8 sub-samples (approximately $1 \times 1 \times 1 \mathrm{~cm}$ dimensions). Sub-samples were wrapped in pre-coded aluminium foils and kept at $60^{\circ} \mathrm{C}$ in another oven until the panel evaluation. The evaluations were made by eight trained panellists (four men and four women), who had at least two years' experience for meat sensory assessment. The panel room had eight cabins separated from each other by barriers, and the entire room was lit with red fluorescent light. Panel evaluation was carried out in twelve sessions. In each session, 10 cooked sub-samples ( 2 breed $\times 5 \mathrm{SW}$ groups) were presented to each panellist. Sensory characteristics of sub-samples were assessed by eight-point category scale described by Sañudo et al. (1998). The panellists assessed tenderness, juiciness, lamb odour and flavour intensity (scale $1=$ extremely tough, extremely dry, no odour and no flavour; scale $8=$ extremely tender, extremely juicy, very strong lamb odour and very strong flavour) (Sañudo et al., 1998). Panellists were served unsalted crackers and water to refresh their mouths between each sub-sample evaluation.

\section{Statistical analyses}

Normal distribution of data was controlled by applying Shapiro-Wilk test. As the lambs of two breeds were finished in different locations with different environmental conditions and were slaughtered in different slaughterhouses, data of Kivircik and Kangal Akkaraman lambs were analysed separately to avoid the possible confounding. In the analyses of carcass and instrumental meat quality data, one-way ANOVA and Duncan multiple comparison tests were applied for comparison of SW groups within each breed. The mathematical description of the model was:

$$
\gamma_{i j}=\mu+a_{i}+e_{i j}
$$

where: $\gamma_{i j}$ is the $i j^{\text {th }}$ observation, $\mu$ is the general mean, $a_{i}$ is the fixed effect of $i^{\text {th }}$ $\mathrm{SW}$ group $(i=20,28,36,44$ and $52 \mathrm{~kg}), e_{i j}$ is random error. 
Data for sensory characteristics were analysed using the General Linear Model (GLM) included the fixed effects of SW, panellist, session and significant two-way interactions between these effects. The cooked meat sample was the experimental unit for sensory data.

\section{Results}

\section{Slaughter and carcass characteristics}

SW had a significant influence on dressing percentage in both breeds (Table 1). In Kivircik lambs, both DP1 and DP2 were higher in SW-36 and SW-44 groups compared to the SW-20 and SW-28 groups. On the other hand, in Kangal Akkaraman lambs, the highest DP1 was observed in SW-28 group. When the weight of tail fat was excluded from the carcass weight, dressing percentage of SW-44 and SW-52 groups was lower than SW-20, SW-28 and SW-36 groups in Kangal Akkaraman lambs.

$L D$ muscle section area significantly increased as SW rose until $44 \mathrm{~kg}$ in lambs of both breeds (Table 2). In Kivircik lambs, BFT gradually increased with increasing SW. On the other hand, there was no increase in backfat thickness up to $52 \mathrm{~kg}$ in Kangal Akkaraman lambs. The backfat thickness of the SW-52 group lambs was higher compared to other SW groups. While the tail fat proportion in Kivircik lambs increased by up to $36 \mathrm{~kg}$, there was a decrease in tail fat proportion in SW of $52 \mathrm{~kg}$. In Kangal Akkaraman lambs, the tail fat proportion increased as the SW increased. When SW increased from $28 \mathrm{~kg}$ to $36 \mathrm{~kg}$, KKCF proportion increased in Kivircik lambs, while it decreased in Kangal Akkaraman lambs. There was a gradual increase in carcass conformation and fatness scores in Kivircik lambs with increasing slaughter weight. In Kangal Akkaraman lambs, conformation score increased up to SW of $44 \mathrm{~kg}$. While the differences between the SW-28, SW-36 and SW-44 groups in terms of fatness score were not significant, a significant increase in carcass fatness score was detected when the SW was increased to $52 \mathrm{~kg}$ in Kangal Akkaraman lambs.

\section{Meat instrumental quality}

In lambs of both breeds, the effects of $\mathrm{SW}$ on meat $\mathrm{pH}_{24}$, cooking loss, WBSF and meat yellowness were not significant (Table 3). Meat drip loss value in Kangal Akkaraman lambs was lower in SW-52 group compared to the lambs of SW-20 and SW-28 groups. As the SW increased in Kivircik lambs, expressed juice also increased. However, in Kangal Akkaraman lambs, expressed juice increased up to $\mathrm{SW}$ of $36 \mathrm{~kg}$, while an additional increase of SW did not affect expressed juice value. As SW increased in Kivircik lambs, there was a significant decrease in meat $\mathrm{L}^{*}$ value and an increase in $\mathrm{a}^{*}$ value. In Kangal Akkaraman lambs, meat of SW-20 and SW-28 groups had higher $\mathrm{L}^{*}$ values, and lower a* and $\mathrm{C}^{*}$ values than those of other SW groups. 


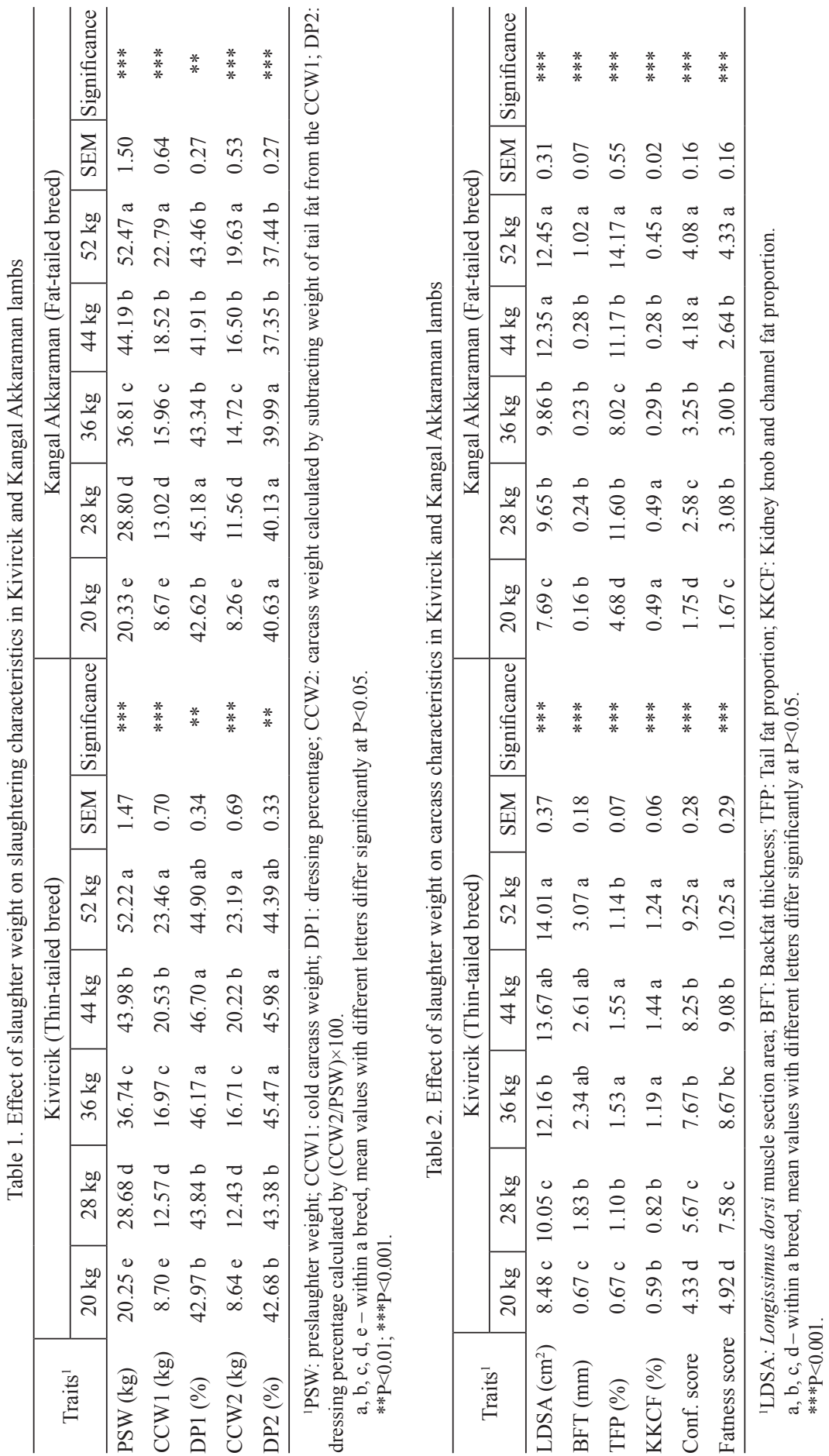




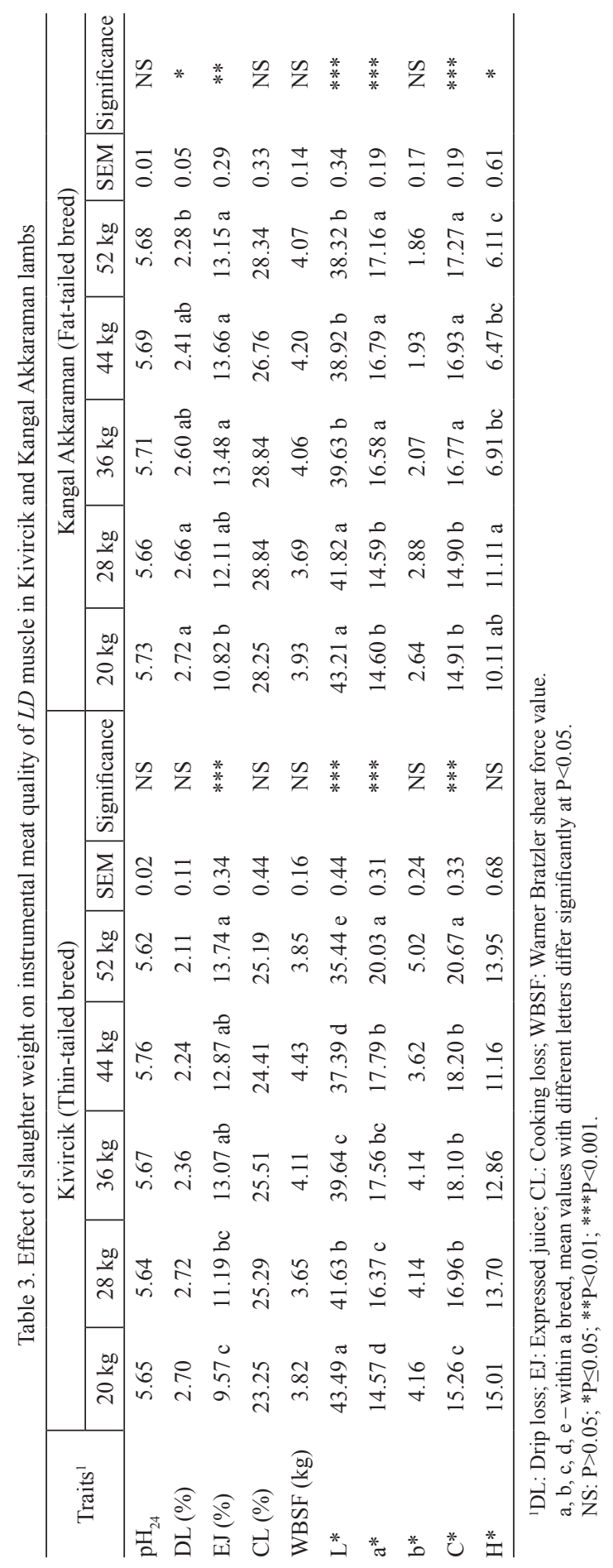




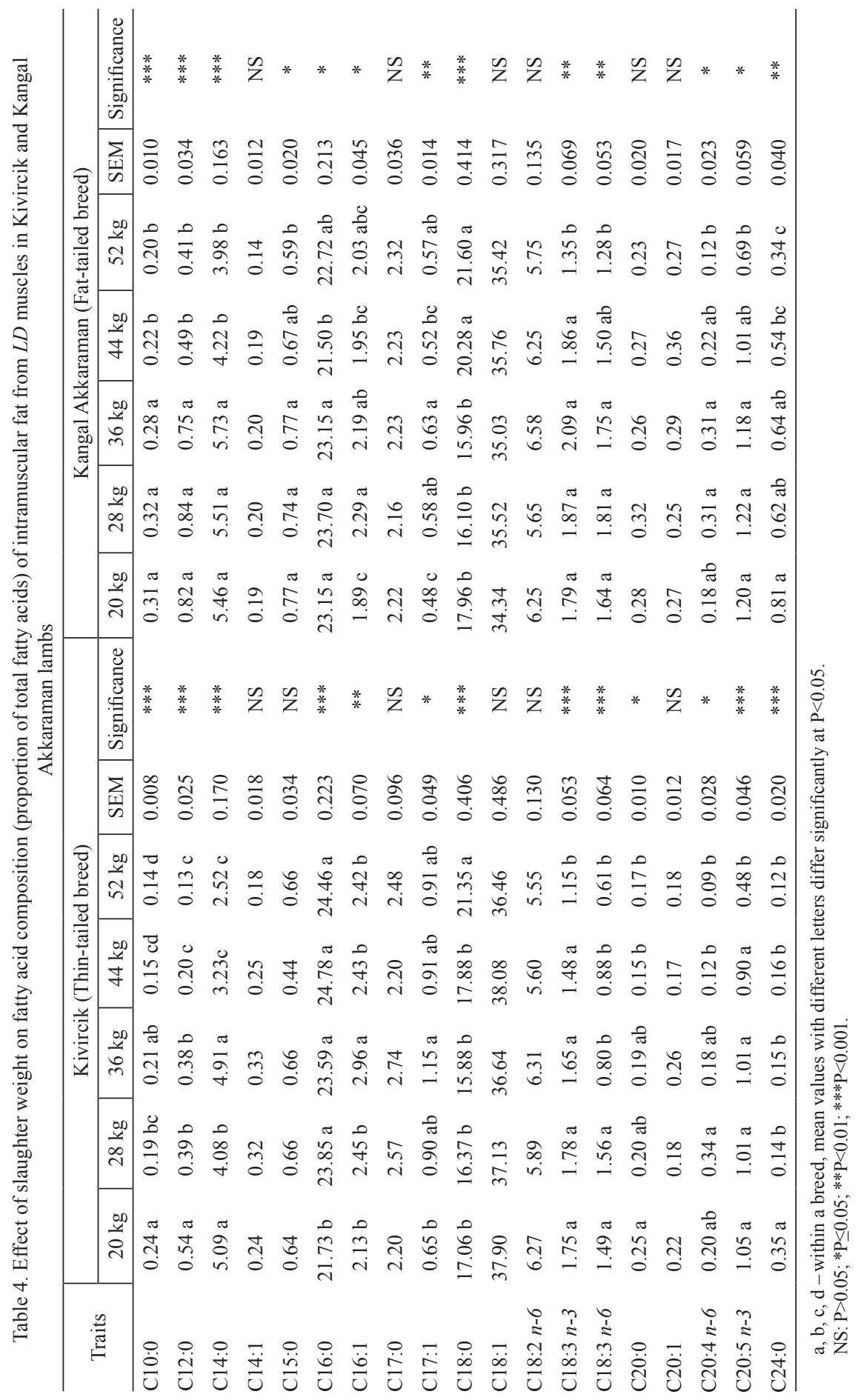




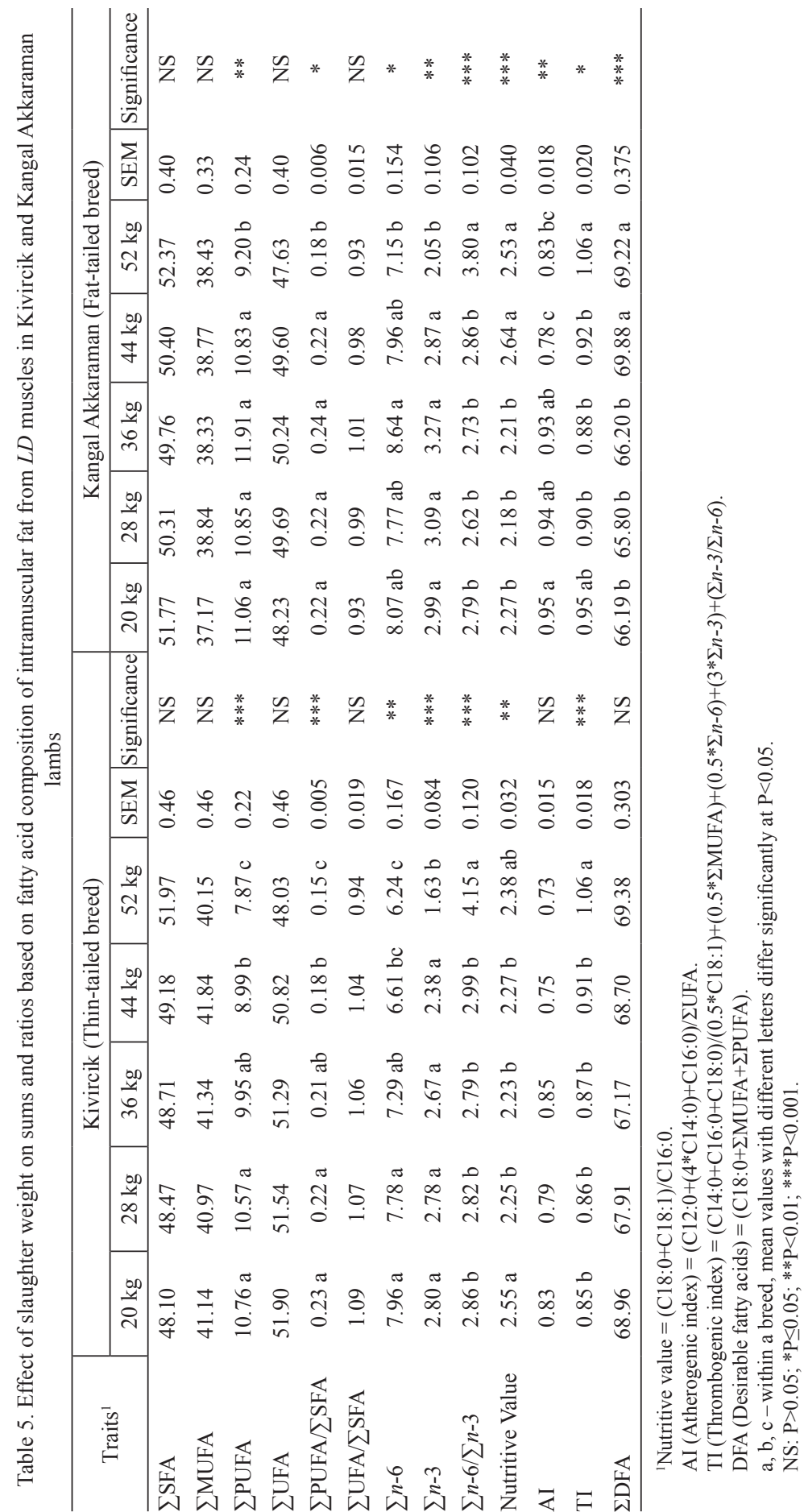




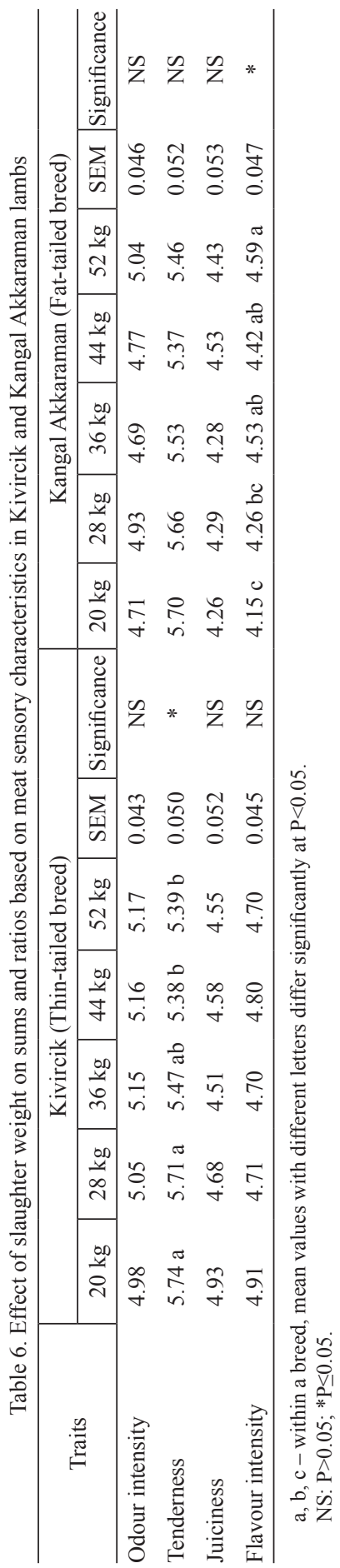




\section{Fatty acids}

SW had a significant influence on proportions of individual saturated fatty acids (SFA), except C15:0 and C17:0 for Kivircik lambs and C17:0 and C20:0 for Kangal Akkaraman lambs (Table 4). However, the proportion of $\Sigma$ SFA was not influenced by SW group in both Kivircik and Kangal Akkaraman lambs (Table 5). In both breeds, SW significantly affected proportions of C16:1 and C17:1. Lambs of SW-36 group had the highest values for these monounsaturated fatty acids (MUFA) in Kivircik breed and for C17:1 in Kangal Akkaraman breed. On the other hand, SW had no influence on the proportions of other individual MUFAs and $\Sigma$ MUFA in lambs of both breeds.

Meat of SW-52 lambs had lower levels for the proportion of C18:3 n-3 compared to other SW groups in both breeds (Table 4). Proportion of C20:5n-3 was also lower in SW-52 lambs compared to other SW groups in Kivircik breed and to SW-20, SW28 and SW-36 groups in Kangal Akkaraman lambs. SW-52 lambs had also the lowest proportion of total polyunsaturated fatty acids (PUFA) and $\Sigma$ PUFA / $\Sigma$ SFA ratio in Kangal Akkaraman lambs. In Kivircik lambs, proportion of $\Sigma$ PUFA and $\Sigma$ PUFA/ $\Sigma$ SFA ratio were lower in SW-44 and SW-52 groups than SW-20 and SW-28 groups. In meat samples of both breeds, SW-52 groups had a lower $\Sigma n-3$ proportion and a higher $\Sigma n-6 / \Sigma n-3$ ratio than other SW groups. In Kangal Akkaraman meats, nutritive value and proportions of desirable fatty acids were higher in SW-44 and SW-52 groups compared to the other SW groups. The thrombogenic index value was highest in SW-52 group in lambs of both breeds.

\section{Meat sensory assessment}

Among investigated sensory characteristics, the influence of SW was significant only on tenderness in Kivircik lambs and on flavour intensity in Kangal Akkaraman lambs (Table 6). In Kivircik breed, meats of SW-20 and SW-28 groups were evaluated more tender than lambs of SW-44 and SW-52 groups by panellists. In Kangal Akkaraman breed, flavour intensity of SW-52 lambs was higher than SW-20 and SW-28 groups.

\section{Discussion}

\section{Slaughter and carcass characteristics}

In Turkey, lamb carcasses are often priced out based on their weights. Therefore, the high dressing percentage is a commercially desirable situation. Both DP1 and DP2 significantly increased as SW rose until $36 \mathrm{~kg}$ in Kivircik lambs, but further increases were not observed at higher slaughter weights. Such a trend was not found in Kangal Akkaraman lambs. Similar to the present results determined for Kivircik lambs, numerous authors reported an increase in DP of lamb carcasses with increasing SW (Ekiz et al., 2020; Kaić et al., 2016; Santos-Silva et al., 2002; Velasco et al., 2000). In previous studies, DP variations among lambs slaughtered at different weights/ages were usually explained by differences in terms of fatness level (Assan, 2020; Ekiz et al., 2016) and/or proportion of non-carcass components like a gastroin- 
testinal tract, skin and head (Budimir et al., 2018; Ekiz et al., 2020; Kaić et al., 2016). While the DP is generally decreased with increasing the non-carcass components, it improves in parallel with the rises in carcass fatness level (Assan, 2020). Velasco et al. (2000) found an increase in DP as SW increased in Talaverana lambs. According to the authors, this result is due to the fact that the increase in carcass weight is higher than the increase observed in offal weights. In the current study, DP had high and significant correlation $(\mathrm{r}=-0.693 ; \mathrm{P}<0.001)$ with proportion of gastrointestinal tract in Kivircik lambs. Therefore, it can be considered that variation in proportion of gastrointestinal tract might be one of the reasons of differences among SW groups in terms of DP in Kivircik lambs. On the other hand, the correlation coefficient between $\mathrm{DP}$ and backfat thickness was $\mathrm{r}=0.417(\mathrm{P}<0.001)$ in Kivircik and $\mathrm{r}=0.282(\mathrm{P}=0.029)$ in Kangal Akkaraman lambs. These results indicate that the carcass fatness may also contribute to the increase in DP as SW increases in Kivircik lambs. A lower DP2 in SW-44 and SW-52 groups in Kangal Akkaraman lambs may be due to the higher proportion of tail fat in these groups. These results also indicate obviously low tail fat-free carcass yield in weights above $44 \mathrm{~kg}$ in Kangal Akkaraman lambs. The DP values found in the current study were consistent with the values reported for Kivircik (Ekiz et al., 2012 a, 2019 b, 2020; Yalcintan et al., 2018) and Akkaraman (Karabacak and Boztepe, 2007) lambs slaughtered at similar weights.

Excessively fat carcasses are not preferred by the butchers, as customers often demand to trim off the excess fat without any payment for this. Therefore, determination of SW is of great importance for the profitability of lamb production. In Kivircik lambs, backfat thickness and fatness score gradually increased in parallel with the increase in SW. On the other hand, the increase in the tail fat and KKCF proportions was observed by up to $36 \mathrm{~kg}$. These results indicate that, up to $36 \mathrm{~kg}$ in Kivircik lambs, there was an increase in both internal and external fat tissues of the carcass, but more fat accumulation in the external surface of the carcass in later weights. Aksoy and Ulutaş (2015) also reported that backfat thickness increased gradually as the SW increased up to $45 \mathrm{~kg}$ for thin-tailed Karayaka lambs and difference between 45 and $50 \mathrm{~kg}$ SW groups was insignificant.

In Kangal Akkaraman lambs, differences for backfat thickness among SW-20, SW-28, SW-36 and SW-44 groups were not significant. But, when the SW increased to $52 \mathrm{~kg}$, backfat thickness increased statistically. In a previous study (Tufan and Akmaz, 2001), differences among lambs slaughtered at $30 \mathrm{~kg}, 35 \mathrm{~kg}$ and $40 \mathrm{~kg}$ in terms of backfat thickness were also not significant. When the SW increased from 44 $\mathrm{kg}$ to $52 \mathrm{~kg}$, there were also significant increases in proportions of tail fat and KKCF and subjective fatness score. These results indicate an evident increase of fatness in weights above $44 \mathrm{~kg}$ in Kangal Akkaraman lambs. Also, Şahin and Akmaz (2002) found similar backfat thickness and KKCF proportion for Akkaraman lambs slaughtered at 35, 40 and $45 \mathrm{~kg}$, and an increase in carcass fatness when SW increased to $50 \mathrm{~kg}$.

There was a gradual increase in $L D$ muscle section area and conformation score with increasing SW in Kivircik lambs. Similar trends for $L D$ muscle section area were previously reported for Karayaka male lambs slaughtered at 30, 35, 40, 45 and $50 \mathrm{~kg}$ (Aksoy and Ulutaş, 2015). However, in Kangal Akkaraman lambs, LD muscle 
section area and conformation score increased as SW increased until $44 \mathrm{~kg}$, and differences between SW-44 and SW-52 groups were not significant. When these results are evaluated together with results of fatness score, it is concluded that the increase in live weight after $44 \mathrm{~kg}$ in Kangal Akkaraman lambs is mostly with the increase in fat tissue.

\section{Meat instrumental quality}

Meat $\mathrm{pH}_{24}$ values between 5.5 and 5.8 can be evaluated as an acceptable quality level (Hoffman et al., 2003). $\mathrm{pH}_{24}$ values for SW subgroups ranged between 5.62 and 5.76 in Kivircik lambs and between 5.66 and 5.73 in Kangal Akkaraman lambs, therefore these values might be considered within the range of acceptable values. In previous studies, the effect of $\mathrm{SW}$ on meat $\mathrm{pH}$ was in conflict. Although some authors (Beriain et al., 2000 a; Díaz et al., 2003; Ekiz et al., 2019 a) observed significant influence of SW on meat $\mathrm{pH}_{24}$, some other studies found no significant variation among lambs slaughtered at different weight groups (Juárez et al., 2009). In the earlier studies, significant meat $\mathrm{pH}_{24}$ differences among different groups were generally attributed to differences in response to pre-slaughter processes (Hopkins and Fogarty, 1998; Ekiz et al., 2012 a) or differences in glycolytic potential (Hopkins and Fogarty, 1998). One of the reasons for the non-significant SW influence on meat $\mathrm{pH}_{24}$ might be that all lambs were subjected to similar pre-slaughter procedures. The fact that all lambs are subjected to an intensive fattening programme and possibly having similar glycolytic potential may also be effective in similar meat $\mathrm{pH}_{24}$ values determined in SW subgroups.

SW had no influence on drip loss in Kivircik lambs. Cooking loss was also not influenced by SW in both breeds. However, drip loss value of SW-52 group was lower than SW-20 and SW-28 groups in Kangal Akkaraman lambs. Meat of SW-44 and SW-52 lambs had higher expressed juice value than SW-20 lambs in both breeds. Supporting the current results, Vergara et al. (1999) found an increase in expressed juice value with increase in SW for Manchego lambs. In some previous studies (Ekiz et al., 2012 b; Yaranoğlu and Özbeyaz, 2019), it has been reported that levels of expressed juice, drip loss and cooking loss are closely related with meat $\mathrm{pH}_{24}$. Ekiz et al. (2012 b) found significant and negative correlation of $\mathrm{pH}_{24}$ with expressed juice and cooking loss. At higher muscle $\mathrm{pH}$, proteins are able to bind with water more strongly and therefore less water is released (De la Fuente et al., 2010; Ekiz et al., 2012 b). However, in the current study, the correlations of $\mathrm{pH}_{24}$ with expressed juice, drip loss and cooking loss were not significant in both Kivircik and Kangal Akkaraman lambs. On the other hand, Rajkumar et al. (2014) noted that increased meat water holding capacity in heavier lambs might be related to their higher fatness. Indeed, backfat thickness had significant Pearson correlation with drip loss $(\mathrm{r}=0.447 ; \mathrm{P}<0.001)$ and expressed juice $(\mathrm{r}=0.487 ; \mathrm{P}<0.001)$ in Kivircik lambs. KKCF proportion had also a significant correlation with expressed juice $(\mathrm{r}=0.393 ; \mathrm{P}=0.002)$ in Kivircik lambs. In the Kangal Akkaraman lambs, both backfat thickness and KKCF proportion had no significant correlation with expressed juice, drip loss and cooking loss. However, tail fat proportion had significant correlation with drip loss $(\mathrm{r}=-0.327 ; \mathrm{P}=0.012)$ and expressed juice $(\mathrm{r}=0.375 ; \mathrm{P}=0.003)$ in Kangal Akkaraman lambs. Therefore, in the 
condition of the current study, carcass fatness in Kivircik lambs and tail fat proportion in Kangal Akkaraman lambs might be considered as important factors influencing variation in meat water holding capacity.

Meat WBSF was not affected by SW in lambs of both breeds. An increase in fatness may cause a decrease in WBSF (Sañudo et al., 2000; Ekiz et al., 2019 a). Slaughter age may also affect the collagen content and solubility, and therefore WBSF (Maiorano et al., 2009). Beriain et al. (2000 b) noted that meat tenderness tends to decrease with age due to an increase in the number of heat-resistant linkages between the collagen fibres. In the current study, the effect of carcass fatness on WBSF might have been neutralized by the effect of slaughter age which would lead to an insignificant SW effect. Liang et al. (2016) reported that meat samples with WB shear force values greater than $4.22 \mathrm{~kg}(41.4 \mathrm{~N})$, might be considered to be tender by consumers. According to this criterion, the meat of all SW groups, except SW-44 in Kivircik lambs, in the current study might be accepted as tender meat.

Meat colour is an important criterion to judge the quality and freshness of meat at purchase by consumers (Ekiz et al., 2012 a). In the current study, a decrease in L* value and an increase in $\mathrm{a}^{*}$ and $\mathrm{C}^{*}$ values were observed as SW increased in the meat of Kivircik lambs. Similar SW effect was observed in the meat of Kangal Akkaraman lambs only up to $36 \mathrm{~kg}$. But, differences among SW-36, SW-44 and SW-52 groups were not significant regarding $\mathrm{L}^{*}, \mathrm{a}^{*}$ and $\mathrm{C}^{*}$ values. Decreased $\mathrm{L}^{*}$ and increased $\mathrm{a}^{*}$ values as SW rose were also reported previously (Cañeque et al., 2001; Santos-Silva et al., 2002; Díaz et al., 2003; Ekiz et al., 2019 a; Kaić et al., 2016). In addition to the $\mathrm{SW}$ effect, numerous factors such as $\mathrm{pH}_{24}$ (Calnan et al., 2016), slaughter age (Budimir et al., 2018; Calnan et al., 2016; Polidori et al., 2017) and fatness level (Calnan et al., 2017) may also influence meat colour variables. In the current study, the $\mathrm{pH}_{24}$ values in different SW groups were similar in both Kivircik and Kangal Akkaraman lambs. Furthermore, the correlations of $\mathrm{pH}_{24}$ with meat colour variables were not significant (results not shown in tables). Therefore, the differences among SW groups in terms of meat colour variables cannot be explained by $\mathrm{pH}$ effect. Budimir et al. (2018) noted that darkening of lamb meat as SW increases might be due to the increased pigment content with age. Indeed, in the current study, slaughter age has negative and significant correlation $(\mathrm{P}<0.001)$ with meat lightness value $(\mathrm{r}=-0.44$ in Kivircik and $\mathrm{r}=-0.54$ in Kangal Akkaraman lambs), and has positive and significant correlation $(\mathrm{P}<0.001)$ with meat redness value $(\mathrm{r}=0.64$ in Kivircik and $\mathrm{r}=0.55$ in Kangal Akkaraman lambs). On the other hand, meat lightness values were negatively correlated with fatness parameters investigated in the present study (backfat thickness, KKCF proportion and fatness score) in both breeds, while the correlations of meat redness and fatness parameters were positive and significant. Therefore, the significant differences in terms of colour variables among SW groups might be due to the combined effects of slaughter age and fatness level.

There is no study conducted to determine which $\mathrm{L}^{*}$ and $\mathrm{a}^{*}$ levels in lamb meat qualified as acceptable by Turkish consumer. However, in a study conducted in Australia, it was found that consumers consider the $\mathrm{L}^{*}$ value above 34 and a* value above 9.5 as acceptable in lamb meat (Khliji et al., 2010). Although meat colour became darker as SW increased especially in Kivircik lambs in our study, meat L* 
and $\mathrm{a}^{*}$ values of lambs in all SW groups might be considered as acceptable by taking into consideration the report by Khliji et al. (2010).

\section{Fatty acids}

Along with other quality criteria, fatty acid composition in meat is also important in meeting meat acceptability and health criteria. Meats with low levels of saturated fatty acids, trans fatty acids and high levels of unsaturated fatty acids are recommended by experts (Williams, 2000). It has been reported in many previous studies that different breeds exhibit different fatty acid composition (Fisher et al., 2000; Camacho et al., 2017). Therefore, we also aimed to determine the fatty acid composition of fatty-tailed and thin-tailed lambs of different breeds at different slaughter weights.

C18:1 (oleic acid) was the most abundant fatty acid among determined fatty acids in all SW groups in both Kivircik (36.46-38.08\%) and Kangal Akkaraman (34.34-35.76\%) lambs. In terms of their proportional contribution to total fatty acids in meat, C16:0 (palmitic acid) and C18:0 (stearic acid) followed C18:1 in all SW groups. In the different SW groups, these three fatty acids accounted for 76.11$82.27 \%$ and $74.14-79.74 \%$ of the total fatty acid in the meat samples of Kivircik and Kangal Akkaraman lambs, respectively. Supporting this result, the prevalence of sum of these fatty acids were reported about $80 \%$ in $L D$ muscles of Kivircik (Ekiz et al., 2019 a) and Barbarine (Atti and Mahouachi, 2009) lambs.

Results regarding proportions of individual fatty acids showed that meat fatty acid composition changed with increasing slaughter weight. It has been observed that medium chain saturated fatty acids such as C10:0 (capric acid), C12:0 (lauric acid) and C14:0 (myristic acid), which are found in the highest rates in milk (Banskalieva et al., 1989), are higher in the youngest lambs that have recently been weaned and had the lowest slaughter weight in both Kivircik and Kangal Akkaraman lambs. Similar to results from current study, decrease in the C12:0 and C14:0 proportions of intramuscular fat of higher SW of lambs was reported previously by numerous authors (Beriain et al., 2000 a; Díaz et al., 2002; Ekiz et al., 2019 a).

Changes in C16:0 level with increasing slaughter weight showed a different pattern in the two breeds. Meat from thin-tailed Kivircik lambs slaughtered at $20 \mathrm{~kg}$ had the lowest level of $\mathrm{C} 16: 0(\mathrm{P}<0.001)$, while there was no difference among other SW groups $(\mathrm{P}>0.05)$. However, fat-tailed Kangal Akkaraman lambs slaughtered at $44 \mathrm{~kg}$ had lower levels of C16:0 than other SW groups. It is possible to see the differences between fat accumulation between fat-tailed and thin-tailed breeds in terms of C16:0 fatty acids. With the weight gain of the lambs, the fat accumulation in the fat-tailed lambs is in the tail and subcutaneous tissue, while the fat accumulation of thin-tailed lambs is in intramuscular and subcutaneous tissue (Bahnamiri et al., 2018). This fatty acid, which is found intensely in adipose tissue, has, therefore, manifested itself in these two distinctive breeds. Significant differences in C18:0 percentages were observed between the SW-52 and other four SW groups in Kivircik lambs (Table 4). In fat-tailed Kangal Akkaraman lambs, SW-44 and SW-52 groups had higher levels of C18:0 than other SW groups. On the other hand, as a whole, total content of SFA did not significantly change in relation to slaughter weight in both breeds $(\mathrm{P}>0.05)$. 
C18:1 is produced by the endogenous desaturation of $\mathrm{C} 18: 0$ and in contrast to C18:0, major fatty acid C18:1 remained constant at about 37\% in Kivircik and about $35 \%$ in Kangal Akkaraman lambs. This result was also reflected in the proportion of total MUFA in intramuscular fat and the effect of SW on the total MUFA proportion was not significant in lambs of both breeds. According to Miltko et al. (2019) reduction in oleic acid is often associated with PUFA supplementation in the diet which is not the case in the current study. Enser et al. (1991) reported that C18:2 n- 6 was very low at birth, increased initially and then slowly decreased. In their study, lambs growing from 32 to $52 \mathrm{~kg}, \mathrm{C} 18: 2 n-6$ fell from 7.0 to $5.4 \%$ whilst C18:0 increased from 17.2 to $26.3 \%$ and similar pattern was observed in our case. The proportion of C18:3 n-3 (linolenic acid) was lower in 52-SW groups than the other SW groups in both breeds. Similar to C18:3n-3, its longer chain product C20:5n-3 (EPA) was found at lowest level in SW-52 groups. During early growth $n-3$ fatty acids level increases and continuously decreases afterwards. Neutral lipid fractions which increase with increasing fatness are more saturated, therefore diluting the proportion of long-chain PUFA compared with animals of lower fatness (De Smet et al., 2004). Moreover, in Kivircik lambs, the total PUFA proportion and the $\Sigma$ PUFA/ $\Sigma$ SFA ratio were lower in SW-44 and SW-52 groups than those of SW-20 and SW-28 groups. Significantly lower levels of these parameters were detected in SW-52 group compared to other SW groups in Kangal Akkaraman lambs. These results agreed with previous results reported by Marino et al. (2008) and Camacho et al. (2017) as total PUFA percentage decreased with increase in SW.

The $\Sigma$ PUFA/ $\Sigma$ SFA ratios ranged between 0.15 and 0.23 in Kivircik lambs and between 0.18 and 0.24 in Kangal Akkaraman lambs. These levels were lower according to Department of Health (1994) guidelines, which recommends a value of 0.45 for diet. Moreover, the level of $\Sigma n-6 / \Sigma n-3$ ratio was beneficially lower in all SW groups of both breeds than recommended value $(<4)$, except SW-52 group of Kivircik breed (4.15). Also, the meat of SW-52 lambs in both breeds may be less beneficial for human health with their lower $\Sigma n-3$, and higher TI values.

\section{Meat sensory assessment}

In Kivircik lambs, the panellists evaluated the meat of SW-20 and SW-28 groups as tender compared to those in SW-44 and SW-52 groups. This result contradicts the finding of WBSF. Variation regarding meat tenderness between instrumental analysis and sensory evaluation may be caused by different methods used in meat cooking. One of the reasons of tougher meat in SW-44 and SW-52 lambs might be the decrease in the amount of soluble collagen with increasing age and the increase in the number of heat-resistant linkages between the collagen fibres (Beriain et al., $2000 \mathrm{~b}$ ). Supporting the current results, Ekiz et al. (2019 a) found no significant differences among the meat of Kivircik lambs slaughtered at $25 \mathrm{~kg}, 30 \mathrm{~kg}$ and $35 \mathrm{~kg}$ weights regarding juiciness, odour and flavour intensity.

In Kangal Akkaraman breed, flavour intensity in the meat of SW-52 lambs was higher than those of SW-20 and SW-28 groups. Moreover, there was a tendency for significant odour intensity $(\mathrm{P}=0.067)$. Supporting the current result, Jeremiah et al. (1998) found an improvement in flavour profile of lamb meat with increasing SW. 
In both breeds, odour intensity and juiciness perception of panellists were not affected from SW. Similar SW influence on odour intensity and juiciness scores were previously reported by Lloyd et al. (1980) for Targhee and Suffolk $\times$ Targhee lambs, by Rajkumar et al. (2014) for Muzaffarnagari lambs and by Ekiz et al. (2019 a) for Kivircik lambs.

\section{Conclusion}

Results of the study indicate that slaughter weight has an evident influence on carcass and meat quality characteristics in both Kivircik and Kangal Akkaraman lambs. In Kivircik lambs, slaughtering at $20 \mathrm{~kg}$ and $28 \mathrm{~kg}$ resulted in better meat colour, $\sum$ PUFA, $\sum$ PUFA/ $\sum$ SFA, $\sum n-6$ and sensory tenderness compared to heavier groups. Therefore, if the main production goal is only to obtain high-quality lamb meat as a luxury product, it may be preferred to slaughter Kivircik lambs at $20 \mathrm{~kg}$ and $28 \mathrm{~kg}$. However, lower dressing percentage and carcass weight in SW-20 and SW-28 groups may result in insufficient utilisation of meat production potential of lambs. When the heaviest groups are compared with each other, lambs of SW-44 and SW-52 groups had similar values in terms of longissimus dorsi muscle section area, backfat thickness and KKCF proportion. However, certain carcass (the subjective fatness score, dressing percentage) and meat quality (lightness, $\sum$ PUFA, $\sum \mathrm{PUFA} / \sum \mathrm{SFA}, \sum n-3$ values and the highest redness, chroma, $\sum n-6 / \sum n-3$ ratio and thrombogenic index values) characteristics were adversely influenced when lambs were slaughtered at $52 \mathrm{~kg}$. Therefore, slaughtering Kivircik lambs at about $44 \mathrm{~kg}$ weight could be recommended to obtain as many quality lamb carcasses as possible without any negative influence on meat quality.

A somewhat similar pattern of SW effect was also observed in Kangal Akkaraman lambs. Slaughtering of lambs at $20 \mathrm{~kg}$ and $28 \mathrm{~kg}$ provided better meat quality but caused lower carcass weight. On the other hand, slaughtering Kangal Akkaraman lambs at $52 \mathrm{~kg}$ did not provide any advantage regarding $L D$ muscle section area and conformation score; furthermore, fattier carcasses were obtained. Also, considering the fatty acid composition, meat of SW-52 lambs may be considered less healthy. Therefore, as in Kivircik lambs, slaughtering Kangal Akkaraman lambs at about 44 $\mathrm{kg}$ weight might be recommended.

\section{References}

A k s o y Y., U lu ta ş Z. (2015). Effect of different slaughter weights on slaughter and carcass traits of male Karayaka lambs reared under intensive production system. Turjaf, 3: 406-412.

A k s oy Y., Uğurlu M., Önenç A., Şirin E., Şen U., Çi çek Ü., Ulutaş Z., Kuran M. (2018). Meat production characteristics of Turkish native breeds: I. Fattening, slaughter and carcass traits of lambs. S. Afr. J. Anim. Sci., 48: 665-672.

A ks oy Y., Uğurlu M., Önenç A., Ş irin E., Ş en U., Çiçek Ü., Ulutaş Z., Kuran M. (2019). Meat production characteristics of Turkish native breeds: II. meat quality, fatty acid, and cholesterol profile of lambs. Arch. Anim. Breed., 62: 41-48. 
Anonymous (2009). Turkish farm animal genetic resources catalogue. Republic of Turkey, Ministry of Food, Agriculture and Livestock. General directorate of agricultural research and policies. https://www.tarimorman.gov.tr/TAGEM/Belgeler/yayin/Katalog\%20T\%C3\%BCrk\%C3\%A7e.pdf (accessed at 09 November 2020).

A s s a n N. (2020). Sex, age of animal and weight at slaughter as explanatory variables for carcass and meat quality properties in goats and sheep production. Sci. J. Rev., 9: 634-643.

Atti N., Mahouachi M. (2009). Effects of feeding system and nitrogen source on lamb growth, meat characteristics and fatty acid composition. Meat Sci., 81: 344-348.

Bahnamiri H.Z., Zali A., Ganjkhanlou M., Sadeghi M., Shahrbabak H.M. (2018). Regulation of lipid metabolism in adipose depots of fat-tailed and thin-tailed lambs during negative and positive energy balances. Gene, 641: 203-211.

B a n s ka li eva V., Shind a r k a Z., D i mov V. (1989). Fatty acid composition of various depot fats of lambs. Proc. 35th International Congress on Meat Science and Technology, Copenhagen, Denmark, 3: 1222-1229.

B eria in M.J., Hor c a d a A., Purro A., Lizas o G., Chas co J., Mendizabal J.A. (2000 a). Characteristics of Lacha and Rasa Aragonesa lambs slaughtered at three live weights. J. Anim. Sci., 78: 3070-3077.

B eriain M.J., Purroy A., Treacher T., B a s P. (2000 b). Effect of animal and nutritional factors and nutrition on lamb meat quality. In: Sheep and goat nutrition: Intake, digestion, quality of products and rangelands, Ledin I., Morand-Fehr P. (eds.). CIHEAM, Zaragoza, Spain, pp. 75-86.

B ud i m ir K., Trombett a M.F., Franci on i M., Toderi M., D'O t t a vio P. (2018). Slaughter performance and carcass and meat quality of Bergamasca light lambs according to slaughter age. Small Rumin. Res., 164: 1-7.

Calnan H., J a c ob R.H., P ethick D.W., Gardner G.E. (2016). Production factors influence fresh lamb longissimus colour more than muscle traits such as myoglobin concentration and $\mathrm{pH}$. Meat Sci., 119: 41-50.

Caln a n H.B., J a c ob R.H., P e thick D.W., Gard ner G.E. (2017). Selection for intramuscular fat and lean meat yield will improve the bloomed colour of Australian lamb loin meat. Meat Sci., 131: 187-195.

Camacho A., Torres A., Capote J., Mata J., Viera J., Bermejo L.A., Argüe1lo A. (2017). Meat quality of lambs (hair and wool) slaughtered at different live weights, J. Appl. Anim. Res., 45: 400-408.

Cañeque V., Velas co S., Díaz M.T., Pérez C., Huidobro F., Lauzurica S., Manz a n ares C., Gonzale s J. (2001). Effect of weaning age and slaughter weight on carcass and meat quality of Talaverane breed lambs raised at pasture. Anim. Sci., 73: 85-95.

De la Fuente J., Sánchez M., Pérez C., Lauzurica S., Vieira C., de Chávarri G., D i a z M.T. (2010). Physiological response and carcass and meat quality of suckling lambs in relation to transport time and stocking density during transport by road. Animal, 4: 250-258

De S met S., R a e s K., D e me y e r D. (2004). Meat fatty acid composition as affected by fatness and genetic factors: a review. Anim. Res., 53: 81-98.

Department of Health (1994). Report on Health and Social Subjects No. 46. Nutritional aspects of cardiovascular disease. HMSO, London.

Díaz M.T., Velas co S., Caneque V., Lauzurica S., Huidobro F., Perez C., Gonzale s J., M a n z a n a re s C. (2002). Use of concentrate or pasture for fattening lambs and its effect on carcass and meat quality. Small Rumin. Res., 43: 257-268.

Díaz M.T., Velasco S., Pérez C., Lauzurica S., de Huidobro R.F., Cañeque V. (2003). Physico-chemical characteristics of carcass and meat Manchego-breed suckling lambs slaughtered at different weights. Meat Sci., 65: 1085-1093.

Ekiz B., Yilmaz A., Ozcan M., Kaptan M., Han oglu H., Erdogan I., Yalcintan H. (2009). Carcass measurements and meat quality characteristics of Turkish Merino, Ramlic, Kivircik, Chios and Imroz lambs raised under an intensive production system. Meat Sci., 82: 64-70.

Ekiz B., Ergül Ekiz E., Yalcintan H., K o cak O., Yil maz A. (2012 a). Effects of suckling length $(45,75$ and $120 \mathrm{~d})$ and rearing type on cortisol level, carcass and meat quality characteristics in Kivircik lambs. Meat Sci., 92: 53-61. 
Ekiz B., Ergül Ekiz E., Kocak O., Yalcintan H., Yilmaz A. (2012 b). Effect of preslaughter management regarding transportation and time in lairage on certain stress parameters, carcass and meat quality characteristics in Kivircik lambs. Meat Sci., 90: 967-976.

E k i z B., K o c a k O., Ya l c in ta n H., Y i l m a z A. (2016). Effects of suckling duration on growth, slaughtering and carcass quality characteristics of Kivircik lambs. Trop. Anim. Health Prod., 48: 395-401.

Ekiz B., Y ilmaz A., Yakan A., Han og lu H., Ka p t a n C. (2018). Breed influence on finishing performance and meat fatty acid composition in lambs raised under an intensive production system. Large Anim. Rev., 24: 121-128.

Ekiz B., Yilmaz A., Yalcintan H., Yakan A., Kocak O., Ozcan M. (2019 a). The effect of production system and finish weight on carcass and meat quality of Kivircik lambs. Ann. Anim. Sci., 19: 517-538.

Ekiz B., A tal ay H., A k in P.D., O zturk N., B irki ye M., Yil maz A. (2019 b). Carcass and meat quality of Karacabey Merino and Kivircik lambs under an intensive finishing system. S. Afr. J. Anim. Sci., 49: 790-798.

Ekiz B., Yilmaz A., Ya l c in tan H., K o c a k O., O z c a n M. (2020). The effect of final weight on slaughtering and carcass quality characteristics of lambs in concentrate-based or pasture-based production systems. Large Anim. Rev., 26: 67-72.

En s e r M. (1991). Animal carcass fats and fish oils. In: Analysis of oil seeds, fats and fatty foods, Russel J.B., Pritchard J.L. (eds.) Elsevier Applied Science, Barking, UK, pp. 329.

European Union (1992). Council Regulation (EEC) No 2137/92 of 23 July 1992 concerning the Community scale for the classification of carcases of ovine animals and determining the Community standard quality of fresh or chilled sheep carcases and extending Regulation (EEC) No 338/91. Official Journal L 214, 30/07/92.

European Union (1993). Commission Regulation (EEC) No 461/93 of 26 February 1993 laying down detailed rules for the Community scale for the classification of carcases of ovine animals. Official Journal L 049, 27/02/93.

FAO (2020). Food and Agricultural Organisation (FAO). Available at: http://www.fao.org/faostat/ en/\#data/QA (Accessed at 09.11.2020).

F isher A.V., Enser M., Richardson R.I., Wood J.D., Nute G.R., Kurt E. (2000). Fatty acid composition and eating quality of lamb types derived from four diverse breed $\times$ production systems. Meat Sci., 55: 141-147.

Gur s o y O. (2006). Economics and profitability of sheep and goat production in Turkey under new support regimes and market conditions. Small Rumin. Res., 62: 181-191.

Hoffman L.C., Muller M., Cloet e S.W.P., S chmidt D. (2003). Comparison of six crossbred lamb types: sensory, physical and nutritional meat quality characteristics. Meat Sci., 65: 1265-1274.

H o n i k e 1 K.O. (1998). Reference methods for the assessment of physical characteristics of meat. Meat Sci., 49: 447-457.

H o p k in s D.L., F o g a r t y N.M. (1998). Diverse lamb genotypes-2. Meat pH, colour and tenderness. Meat Sci., 49: 477-488.

J e re miah L.E., Tong A.K.W., Gibs on L.L. (1998). The influence of lamb chronological age, slaughter weight, and gender. Flavor and texture profiles. Food Res. Int., 31: 227-242.

Johansen J., A a stve it A., Egelandsdal B., Kva a l K., R o e M. (2006). Validation of the EUROP system for lamb classification in Norway, repeatability and accuracy of visual assessment and prediction of lamb carcass composition. Meat Sci., 74: 497-509.

Juárez M., Horcada A., Alcalde M.J., Valera M., Polvillo O., Molina A. (2009). Meat and fat quality of unweaned lambs as affected by slaughter weight and breed. Meat Sci., 83: 308-313.

Ka ić A., M i o č B., K a s a p A., Levart A. (2016). Physicochemical properties of meat of Lika Pramenka lambs raised under semi-extensive production system: effects of sex, slaughter weight and season. Vet. Arhiv, 86: 229-241.

Karabacak A., B oztepe S. (2007). Comparison of fattening performance of fat tailed and thin tailed sheep breeds. Selcuk J. Agr. Food Sci., 21: 89-95.

K a y a 11 k M.S., B i n g ö 1 M. (2015). All characteristics of Morkaraman sheep. Iğdır Univ. J. Inst. Sci. Tech., 5: 89-97. 
K h a d re A.A.B., K a raba c a k, A. (2018). Comparison of fattening performance and carcass traits measurements of Akkaraman and Awassi male lambs. Selcuk J. Agr. Food Sci., 32: 542-548.

Khliji S., van de Ven R., Lamb T.A., Lanza M., Hopkins D.L. (2010). Relationship between consumer ranking of lamb colour and objective measures of colour. Meat Sci., 85: 224-229.

Li ang R.R., Zhu H., Ma o Y.W., Zhang Y.M., Zhu L.X., Cornforth D.P., Wang R.H., Meng X.Y., Luo X. (2016). Tenderness and sensory attributes of the longissimus lumborum muscles with different quality grades from Chinese fattened yellow crossbred steers. Meat Sci., 112: 52-57.

L 1 o y d W.R., S l y te r A.L., C o s t e 11 o W.J. (1980). Effect of breed, sex and final weight on feedlot performance, carcass characteristics and meat palatability of lambs. J. Anim. Sci., 51: 316-320.

Maiorano G., Ciarlariello A., Cianciullo D., Roychoudhury S., Manchisi A. (2009). Effect of suckling management on productive performance, carcass traits and meat quality of Comisana lambs. Meat Sci., 83: 577-583.

Marino R., Albenzio M., Annicchiarico G., Caroprese M., Muscio A., Santil1 o A., S e vi A. (2008). Influence of genotype and slaughtering age on meat from Altamurana and Trimeticcio lambs. Small Rumin. Res., 78: 144-151.

Martín ez - C e re zo S., S a ñ u d o C.,P a n e a B., M e d e l I., D e 1 fa R., S i e r r a I., B e l trán J.A., C e p e ro R., O 11 e t a J.L. (2005). Breed, slaughter weight and ageing time effects on physicochemical characteristics of lamb meat. Meat Sci., 69: 325-333.

Miltko R., Majewska M.P., B ełżecki G., Kula K., Kowalik B. (2019). Growth performance, carcass and meat quality of lambs supplemented different vegetable oils. Asian-Australas J. Anim. Sci., 32: 767-775.

Polidori P., Pucciarelli S., Cammertoni N., Polzonetti V., Vincenzetti S. (2017). The effects of slaughter age on carcass and meat quality of Fabrianese lambs. Small Rumin. Res., 155: 12-15.

R a j ku m a r V., D a s s G., Verm a A.K., D a s A.K. (2014). Slaughter weight effect on carcass and meat quality of Muzaffarnagari lambs in intensive production system. Indian J. Anim. Sci., 84: 569-574.

Ş a h in E.H., A k m a z A. (2002). Fattening performance, slaughter and carcass characteristics of Akkaraman lambs at different slaughter weights. EJVS, 18: 29-36.

S antos - S ilva J., Mendes I.A., B e s s a R.J.B. (2002). The effect of genotype, feeding system and slaughter weight on the quality of light lambs. 1. Growth, carcass composition and meat quality. Livest. Prod. Sci., 76: 17-25.

S añudo C., Nute G.R., Campo M.M., Maria G., Baker A., S i erra I., Ens er M.E., Wo o d J.D. (1998). Assessment of commercial lamb meat quality by British and Spanish taste panels. Meat Sci., 48: 91-100.

Sañudo C., Alfonso M., Sánchez A., Delfa R., Teixeira A. (2000). Carcass and meat quality in light lambs from different fat classes in the EU carcass classification system. Meat Sci., 56: 89-94.

Tufan M., A k ma z A. (2001). Slaughter and carcass traits of Güney Karaman, Kangal-Akkaraman and Akkaraman lambs at different slaughter weights. Turk. J. Vet. Anim. Sci., 25: 495-504.

TUIK (2020). Turkish Statistical Institute (TUIK) Animal Production Statistics, TS 33873, 2019. Available at: https://data.tuik.gov.tr/Bulten/Index?p=Animal-Production-Statistics-2019-33873 (Accessed at 09 November 2020).

Velasco S., Lauzurica S., Caneque V., Perez C., Huidobro F., Manzanares C., Díaz M.T. (2000). Carcass and meat quality of Talaverana breed sucking lambs in relation to gender and slaughter weight. Anim. Sci., 70: 253-263.

Vergar a H., Molin a A., Galle g o L. (1999). Influence of sex and slaughter weight on carcass and meat quality in light and medium weight lambs produced in intensive systems. Meat Sci., 52: 221-226.

W i 11 i a m s C.M. (2000). Dietary fatty acids and human health. Annal. Zootech., 49: 165-180.

Yalcintan H., Akin P.D., Ozturk N., Avanus K., Muratoglu K., Kocak O., Yil$\mathrm{m}$ a z A., E k i z B., (2018). Effect of lairage time after $2 \mathrm{~h}$ transport on stress parameters and meat quality characteristics in Kivircik ewe lambs. Small Rumin. Res., 166: 41-46. 
Yaranoğlu B., Özbeyaz C. (2019). Quality characteristics and fatty acid profiles of Bafra, Akkaraman, and Bafra $\times$ Akkaraman F1 lamb meat. Turk J. Vet. Anim. Sci., 43: 380-390.

Received: 12 VIII 2020

Accepted: 18 I 2021 